\title{
MEMBANGUN SISTEM INFROMASI E-LEARNING PERKULIAHAN STMIK WICIDA SAMARINDA
}

\author{
Basrie $^{1)}$, Amelia Yusnita ${ }^{2)}$ \\ ${ }^{1,2}$ Sistem Informasi, STMIK Widya Cipta Dharma \\ 1,2 J1. Prof. M. Yamin No 25, Samarinda, 75123 \\ E-mail : basrie@wicida.ac.id ${ }^{1)}$, amelia@wicida.ac.id ${ }^{2)}$
}

\begin{abstract}
ABSTRAK
Penggunaan electronic learning (e-learning) dalam perkuliahan sudah banyak diterapkan di beberapa perguruan tinggi terutama di STMIK Widya Cipta Dharma. Dengan sistem ini, para mahasiswa dapat mengakses materi kuliah dan tugas secara online. E-learning sangat membantu dalam sistem perkuliahan bagi dosen dan mahasiswa, terutama bagi dosen atau mahasiswa yang tidak dapat hadir, tetapi tetap dapat mendapatkan materi perkuliahan melalui media online ini. Namun pada kenyataannya di lapangan penggunaan e-learning di kampus masih belum efektif dan belum digunakan secara maksimal. Hal ini dikarnakan penggunaan E-learning (dosen dan mahasiwa) pada STMIK Widya Cipta Dharma masih banyak yang belum familiar dan terbiasa menggunakaan sistem E-lerning. Dari permasalahan tersebut maka dibuatlah Sistem Informasi E-learning pada STMIK Widya Cipta Dharma Untuk membantu dalam proses belajar dan mengajar, dan dalam pengujian nanti akan digukakan metode Pengujian Beta agar fungsi dan keguaan dapat terlihat dengan baik dan efektif.
\end{abstract}

Kata Kunci: E-learning, Sistem Informasi, Pengujian Beta

\section{PENDAHULUAN \\ E-learning merupakan salah satu sarana} perkuliahan yang menyediakan berbagai fitur atau tampilan icon yang dapat digunakan untuk mengakses materi, tugas dan project dari dosen yang bersangkutan. E-learning dapat didefinisikan sebagai fasilitas dan dukungan pembelajaran dengan memanfaatkan teknologi informasi dan komunikasi (TIK). E-learning juga merupakan suatu jenis belajar mengajar yang memungkinkan tersampaikannya bahan ajar ke siswa dengan menggunakan media internet, intranet, atau media jaringan komputer lainnya. E-learning merujuk pada penggunaan teknologi internet untuk mengirimkan serangkaian solusi yang dapat meningkatkan pengetahuan dan keterampilan. Oleh sebab itu, dapat disimpulkan bahwa e-learning merupakan sistem pembelajaran melalui media online dengan pemanfaatan teknologi informasi dan komunikasi yang digunakan untuk menyampaikan bahan atau materi ajar dari dosen untuk meningkatkan pengetahuan dan keterampilan mahasiswa.

Berdasarkan pengertian diatas, maka pembelajaran E-learning memiliki beberapa manfaat yang dapat digunakan dalam proses pembelajaran. Pembelajaran dalam hal ini dimaksud untuk menyampaikan materi yang diajarkan dengan memanfaatkan teknologi dan komunikasi sehingga setiap kampus dituntut untuk memanfaatkan teknologi dalam era globalisasi yang berdaya saing. Oleh sebab itu, STMIK Widya Cipta Dhrama telah menerapkan sistem pembelajaran online yang akan dimanfaatkan oleh dosen dan mahasiswa untuk membantu proses pembelajaran. Namun berdasarkan keterangan kepala bagian BAAK STMIK Widya Cipta Dharma menjelaskan bahwa terdapat 40 dosen dan 1300 mahasiswa yang ada di STMIK Widya Cipta Dharma, hanya 3 dosen dan 300 mahasiswa yang memanfaatkan pembelajaran e-learning di kampus. Dari 3 Dosen tersebut Menggunakan E-lerning dengan Moodle, dan sisa desen yang lain kurang paham penggunaan Moodle Keadaan ini sangat memprihatinkan sehingga diperlukan Sistem informasi agar dosen dan mahasiswa yang menggunakan dengan mudah.

\section{RUANG LINGKUP PENELITIAN}

Permasalahan difokuskan pada data:

1. Data Dosen

2. Data Matakuliah

3. Data Mahasiswa

4. Data Kelas

5. Data Perkuliahan

6. Data User

Permasalahan juga difokuskan pada kebutuhan user yang perlu ditampilkan dalam website ini, yaitu:

1. Adanya fasilitas input tugas mahasiswa bagi dosen agar mahasiswa dapat melihat dan mengerjakan tugas yang diberikan oleh Dosen tertentu

2. Adanya Fasilitas Ujian online

3. Adanya Fasilitas Upload Video dan Materi Perkulihan

4. Adanya Fasilitas Input Nilai 


\section{BAHAN DAN METODE}

Penelitian tentang Evaluasi E-lerning yang sama telah banyak dilakukan antara lain :

1. Sistem Informasi Evaluasi Penggunaan E-Learning Sebagai Sistem Perkuliahan Perguruan Tinggi (Studi Kasus: Pt. STMIK Bumigora Mataram (Uswatun Hasanah dan Ismarmiaty, 2017)

2. Evaluasi Penyelenggaraan E-Learning Dalam Pembelajaran Di Sma Negeri Aro Semarang (Baiti Kharisma Sari, 2015)

3. Keefektifan E-Learning Sebagai Media Pembelajaran (Studi Evaluasi Model Pembelajaran E-Learning Smk Telkom Sandhy Putra Purwokerto) (Numiek Sulistyo Hanum, 2013)

Penelitian dari Uswatun Hasanah dan Ismarmiaty. Penelitin yang evaluasi penggunaannya dengan memodelkan faktor penerimaan e-learning dengan model TAM dan dianalisis menggunakan SEM. Hasil simulasi model dibantu dengan perangkat lunak AMOS diperoleh Goodness Of Fit (GOF) pada model penerimaan e-learning melalui uji model secara struktural, analisis faktor konfirmatori (CFA) pengukuran variabel eksogen dan endogen serta analisis model struktural. Akibatnya, model yang telah dibentuk bisa diterima untuk pengujian sistem informasi evaluasi penggunaan e-learning sebagai sistem perkuliahan perguruan tinggi.

Penelitian Baiti Kharisma Sari tentang Evaluasi Penyelenggaraan E-learning dalam Pembelajaran di SMAN 8 Semarang. Latar belakang penelitian ini adalah berdasarkan observasi yang dilakukan di SMAN 8 Semarang menunjukkan adanya ketidaklancaran penyelenggaraan elearning baik dari personal, sarana prasarana, serta belum optimalnya pelaksanaan proses pembelajaran dengan menggunakan e-learning. Tujuan dari penelitian ini adalah untuk mengetahui sejauh mana penyelenggaraan pembelajaran e-learning dilihat dari sudut evaluasi konteks, evaluasi input, evaluasi proses dan evaluasi produk.

Pada penelitian Numiek Sulistyo Hanum, Penelitian yang bertujuan untuk mendeskripsikan standar mutu pelaksanaan elearning sebagai media pembelajaran yang efektif; mengidentifikasi keefektifan perencanaan pembelajaran elearning; mengidentifikasi keefektifan perancangan dan pembuatan materi pembelajaran e-learning; mengidentifikasi keefektifan metode penyampaian pembelajaran e-learning; mengidentifikasi keefektifan pelaksanaan dan interaktivitas pembelajaran e-learning; men-gidentifikasi keefektifan evaluasi pelaksanaan e-learning; mengetahui faktor penghambat dan pendukung pelaksanaan e-learning sebagai media pembelajaran.

Penelitian ini akan dilaksanakan melalui beberapa tahapan pengembangan waterfall sebagai berikut:

1. Analisis data sistem ini bertujuan untuk memberikan gambaran tentang sistem yang diusulkan, menganalisa teknologi yang dibutuhkan.

2. Desain sistem ini bertujuan untuk memberikan gambaran umum tentang sistem yang diusulkan. Desain yang digunakan adalah Diagram Alir (Flowchart).

3. Coding \& Testing dalam hal ini difokuskan pada pembuatan program dan penggunaannya.
4. Pengujian ini menggunakan metode pengujian whitebox. Pengujian ini digunakan untuk memastikan bahwa semua statemen pada program telah dieksekusi paling tidak satu kali selama pengujian dan bahwa semua kondisi logis telah diuji.

5. Pemeliharaan perangkat lunak yang sudah disampaikan kepada pelanggan pasti akan mengalami perubahan. Perubahan tersebut bisa karena mengalami kesalahan karena perangkat lunak harus menyesuaikan dengan lingkungan (periperal atau sistem operasi baru) baru, atau karena pelanggan membutuhkan perkembangan fungsional.

\section{RANCANGAN SISTEM}

Perkulihan yang berjalan pada STMIK Widya Cipta Dharma masih tatapmuka dengan bertemu langsung antara Mahasiwa dan Dosen, dalam kegiatan rutin ini ada beberapa kendala yang terjadi dalam proses Perkulihan yaitu media yang dapat membantu pihak dosen dan mahasiswa mulai dari tatap muka, penyampain tugas, penyampian materi, dan penyampain Nilai yang dilakukan diluar jam perkulihan.

Dari hasil analisis sistem maka didapatkan sebuah rancangan atau desain dari sistem yang akan dibangun. Untuk merancang sebuah sistem digunakan alat bantu pengembangan sistem berupa Flowchart dan Site Map (dapat dilihat pada gambar 1 dan 2)

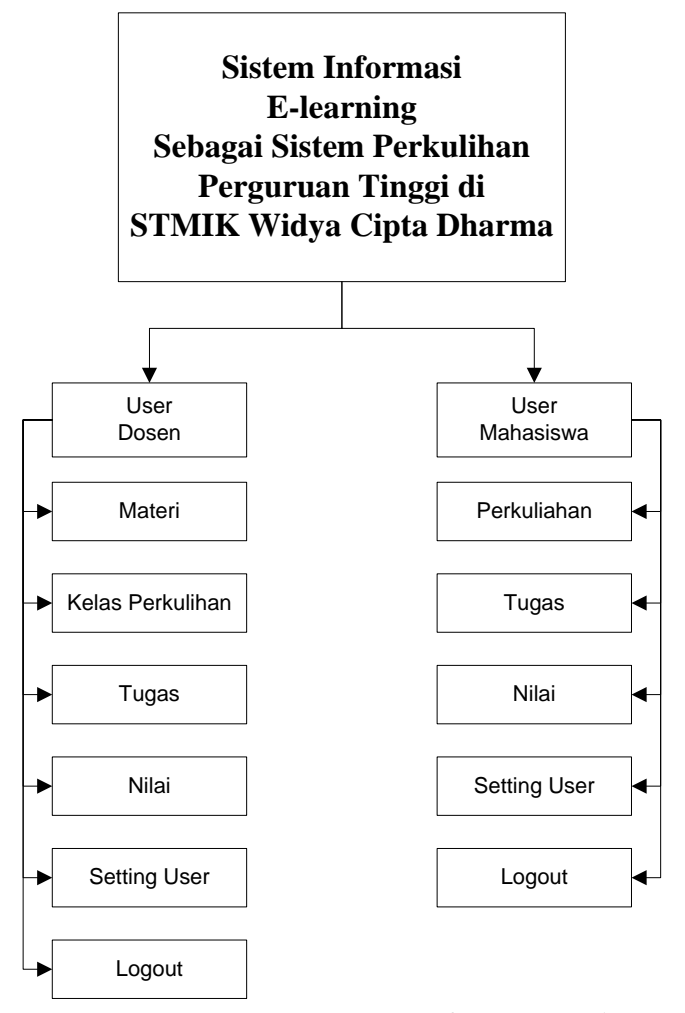

Gambar 1. Site Map Sistem Informasi E-learning 


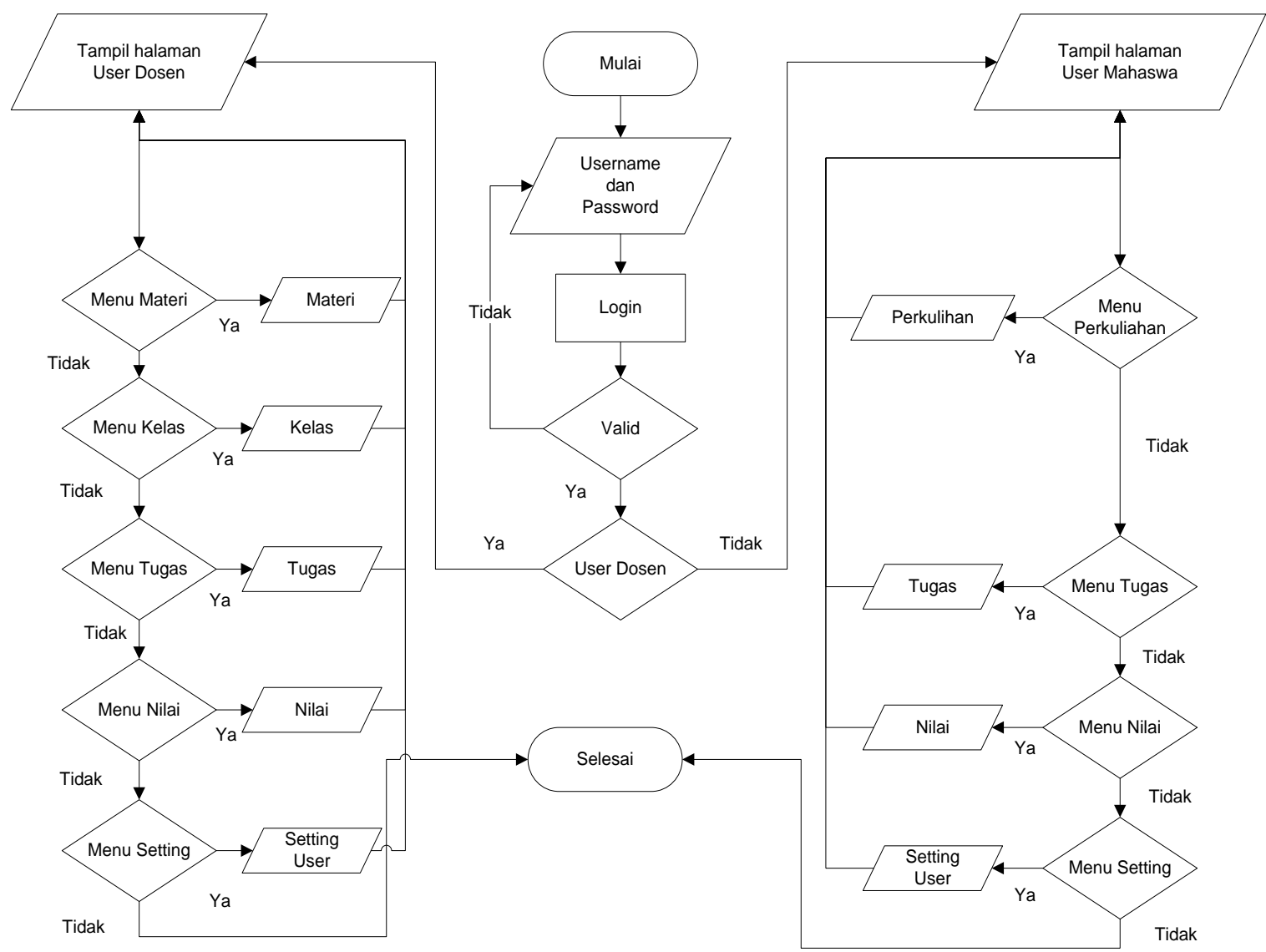

\section{Nama Databse : Elearning_Wicida}

Gambar 2. Flowchart Sistem

Table Dosen
\begin{tabular}{|l|l|l|}
\hline No & Filed & Type Data \\
\hline 1 & NIDN & Varchar(25) \\
\hline 2 & Nama & Varchar( $(60)$ \\
\hline 3 & Gelar_depan & Varchar( 25$)$ \\
\hline 4 & Gelar_belakang & Varchar( $(25)$ \\
\hline 5 & Pendidikan_terakhir & Varchar( 25$)$ \\
\hline 6 & Hp & Varchar(15) \\
\hline 7 & Email & Varchar( 60$)$ \\
\hline 8 & Alamat & Text \\
\hline
\end{tabular}

Table : Kelas

\begin{tabular}{|l|l|l|}
\hline No & Filed & Type Data \\
\hline 1 & Idkelas & Varchar(25) \\
\hline 2 & Nama_kelas & Varchar(60) \\
\hline 3 & kapasitas & int \\
\hline
\end{tabular}

Table : user
\begin{tabular}{|l|l|l|}
\hline No & Filed & Type Data \\
\hline 1 & Username & Varchar $(25)$ \\
\hline 2 & Password & Varchar $(25)$ \\
\hline 3 & group & Varchar $(25)$ \\
\hline
\end{tabular}

\begin{tabular}{|c|c|c|}
\hline No & Filed & Type Data \\
\hline 1 & NIM & Varchar(25) \\
\hline 2 & Nama & Varchar $(60)$ \\
\hline 3 & Kelas & Varchar(25) \\
\hline 4 & Prodi & Varchar(25) \\
\hline 5 & Pendidikan terakhir & Varchar(25) \\
\hline 6 & $\mathrm{Hp}$ & Varchar(15) \\
\hline 7 & Email & Varchar(60) \\
\hline 8 & Alamat & Text \\
\hline
\end{tabular}

Table :Materi
\begin{tabular}{|l|l|l|}
\hline No & Filed & Type Data \\
\hline 1 & Idmateri & Varchar $(25)$ \\
\hline 2 & Idkelas & Varchar(25) \\
\hline 3 & judul & text \\
\hline 4 & File_materi & Varchar $(60)$ \\
\hline 5 & Isi_materi & Text \\
\hline 6 & No_materi & int \\
\hline 7 & NIDN & Varchar $(25)$ \\
\hline 8 & Tanggal & Date \\
\hline
\end{tabular}

Table : kelas_mahasiswa
\begin{tabular}{|l|l|l|}
\hline No & Filed & Type Data \\
\hline 1 & Idkelas & Varchar $(25)$ \\
\hline 2 & NIM & Varchar $(60)$ \\
\hline 3 & Hari & Varchar $(25)$ \\
\hline 4 & Jam & Varchar $(25)$ \\
\hline 5 & ruangan & Varchar(25) \\
\hline
\end{tabular}

Table :Nilai
\begin{tabular}{|l|l|l|}
\hline No & Filed & Type Data \\
\hline 1 & Idnilai & Varchar( 25$)$ \\
\hline 2 & idkelas & Varchar $(60)$ \\
\hline 3 & NIM & Varchar $(25)$ \\
\hline 4 & Nilail & Int \\
\hline 5 & Nilai2 & Int \\
\hline 6 & Nilai3 & Int \\
\hline
\end{tabular}

Table :tugas
\begin{tabular}{|l|l|l|}
\hline No & Filed & Type Data \\
\hline 1 & idtugas & Varcahar(25) \\
\hline 2 & Idkelas & Varchar( 25$)$ \\
\hline 3 & Judul_tugas & Varchar $(60)$ \\
\hline 4 & Jenis_tugas & Varchar $(60)$ \\
\hline 5 & Mulai_tugas & date \\
\hline 6 & Batas_tugas & date \\
\hline
\end{tabular}

Gambar 3. Struktur database

Dapat dilihat pada gambar 3 di atas, adalah desain dari struktur basisdata pada sistem informasi e-learning STMIK Widya Cipta Dharma, dimana tedapat 8 tabel dengan masing-masing field yang saling berkaitan antar tabel. 


\section{IMPLEMENTASI}

Implementasi program merupakan kelanjutan dari tahap perancangan sehingga sebuah sistem yang nyata dan bisa diguknakan seperti membuat desain Form Sistem Informasi.

\subsection{Antarmuka Sistem Informasi E-learning}

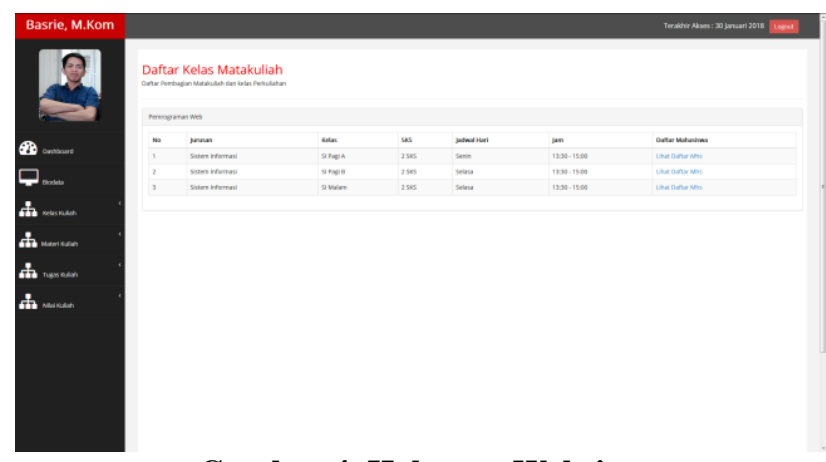

\section{Gambar 4. Halaman Website}

Pada Gambar 4 tampilan Halaman ini berisi daftar menu disebalh kiri, di bagian tegah halaman berisi daftar kelas perkuliahan dari Dosen yang mengajar

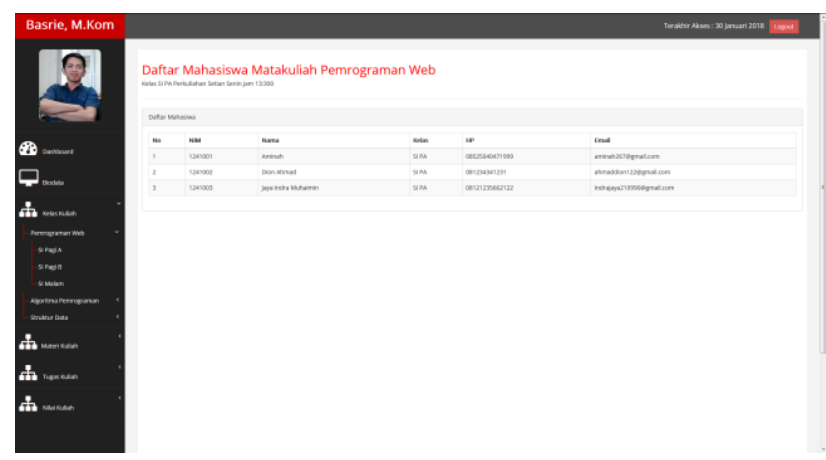

\section{Gambar 5. Halaman Kelas Perkuliahan Mahasiswa}

Pada Gambar 5 tampilan Halaman ini berisi daftar menu disebalh kiri, di bagian tegah halaman berisi daftar Mahasiswa dalam kelas perkuliahan dari Dosen yang mengajar.

\subsection{Pengujian Sistem Informasi E-learning}

Pengujian beta merupakan uji coba sebuah aplikasi secara live didalam suatu lingkungan yang tidak dapat dikontrol oleh pengembang. Uji coba dilakukan dalam bentuk quisioner sederhana yang diisi oleh dosen dan mahasiswa STMIK Widya Cipta Dharma. Dalam penelitian ini uji coba dilakukan pada 5 orang Dosen dan 5 mahasiswa, dimana disajikan 5 pertanyaan yang mengacu pada Halaman Website.
Tabel 1. Hasil Pengujian Beta

\begin{tabular}{|c|c|c|c|c|}
\hline \multirow{2}{*}{ Pertanyaan } & \multicolumn{3}{|c|}{ Jawaban Responden } & \multirow{2}{*}{$\begin{array}{c}\text { Total } \\
\text { Responden }\end{array}$} \\
\hline & Bagus & Cukup & Kurang & \\
\hline $\begin{array}{l}\text { Bagaimana } \\
\text { Tampilan } \\
\text { Website? }\end{array}$ & 7 & 3 & 0 & 10 \\
\hline $\begin{array}{l}\text { Bagaimana } \\
\text { Fitur } \\
\text { Layanan } \\
\text { pada } \\
\text { Website? }\end{array}$ & 7 & 2 & 1 & 10 \\
\hline $\begin{array}{l}\text { Bagaimana } \\
\text { Fungsi } \\
\text { Menu pada } \\
\text { Website }\end{array}$ & 6 & 3 & 1 & 10 \\
\hline $\begin{array}{l}\text { Apakah } \\
\text { Mengakses } \\
\text { web sangat } \\
\text { mudah? }\end{array}$ & 6 & 2 & 2 & 10 \\
\hline $\begin{array}{l}\text { Apakah } \\
\text { website } \\
\text { bermanfaat } \\
\text { untuk } \\
\text { perkuliahan } \\
\text { ? }\end{array}$ & 8 & 1 & 1 & 10 \\
\hline $\begin{array}{c}\text { Total } \\
\text { Jawaban }\end{array}$ & 34 & 11 & 5 & 50 \\
\hline
\end{tabular}

Dari hasil pengujian beta pada tabel 1, dapat ditentukan bobot perhitungan untuk jawaban "kurang" memiliki bobot 1, untuk jawaban "cukup" dengan bobot 2 , dan jawaban "bagus" dengan bobot 3. Maka dapat diambil perhitungan rata-rata persentase nilai responden:

$$
\bar{X}=\frac{34 \times 3+11 \times 2+5 \times 1}{50 \times 3} \times 100=86 \%
$$

Berdasarkan perolehan persentase tersebut didapat persentase adalah $86 \%$, maka web E-learning dapat diterima karena presentasi nilai yang didapat, di atas nilai persentase minimum yaitu $50 \%$ (di atas cukup), dan mendekati angka 100\% (sangat bagus).

\section{KESIMPULAN}

Dari hasil analisis dan pengujian yang digunakan dapat ditarik kesimpulan :

1. Telah dibangunWeb E-Learning pada perkuliahan di STMIK Widya Cipta Dharma agar mempermudah proses belajar dan Mengajar dilingkungan Kampus

2. Metode Pengembangan Sistem dalam membangun Website E-Learning menggunakan Metode Water Fall.

3. Pengujian Pada Pembuatan website menggunakan metode Beta Testing menunjukkan sistem informasi e-learning ini dapat diterima dengan baik 


\section{SARAN}

Saran untuk penelitian dengan judul atau topik yang mengacu kepada sistem e-learning diharapkan sistem yang dibangun dapat memiliki fitur video conference ataupun live chat antara dosen dan mahasiswa. Serta adanya evaluasi dan monitoring dengan permodelan pendekatan Technology Acceptance Model (TAM)

\section{DAFTAR PUSTAKA}

Hasanah, U., Ismarmiaty, I. and Bachtiar, A., 2017, August. Analisis Simulasi Goodness Of Fit (GOF) pada Uji Model Penerimaan E-Learning. In Seminar Nasional Aplikasi Teknologi Informasi (SNATI)

Hanum, N.S., 2013. Keefetifan E-Learning sebagai Media Pembelajaran (Studi Evaluasi Model Pembelajaran E-Learning SMK Telkom Sandhy Putra Purwokerto). Jurnal Pendidikan Vokasi, 3(1).

Qomariah, S., Pratiwi, H. and Arfyanti, I., 2014. Membangun E-Lerning Menggunakan Moodle Pada STMIK Widya Cipta Dharma Samarinda. SEMNASTEKNOMEDIA ONLINE, 2(1), pp.304Widhya, D., \& Ramaiyulis, Penerapan Teknologi Defaunasi untuk Meningkatkan Produksi Air Susu Sapi Perah. Jurnal P \& PT, III (3), 91-96.
Ramadiani, R. and Azainil, A. 2013. Model User Interface Acceptance Untuk Evaluasi E-Learning, Prosiding SeNAIK, pp. 108-114.

Safii, M. and Vidy, V. 2017. Perancangan Sistem Informasi Badan Penjaminan Mutu Internal STMIK Balikpapan Berbasis Website Responsive, Sebatik, 18(1), pp. $10-16$

Sari, B.K., 2015. Evaluasi Penyelenggaraan E-Learning Dalam Pembelajaran Di SMA Negeri Aro Semarang (doctoral dissertation, universitas negeri semarang).

Yulsilviana, E., Yusnita, A. and Ridhuan. S, M. 2016. Sistem Informasi Administrasi Akademik Pada Baak STMIK Widya Cipta Dharma Samarinda Berbasis Web, Sebatik, 16(1), pp. 26-33.

Yulsilviana, E., Basrie, B. and Saputra, A. W. 2017. Implementasi Augmented Reality pemasaran rumah PT. Rika Bersaudara Sakti Menggunakan Metode Marker Based Tracking Pada Brosur Perumahan, Sebatik, 17(1), pp. 11-15.

\section{Publikasi ini dibiayai oleh:}

Direktorat Riset dan Pengabdian Masyarakat

Direktorat Jenderal Penguatan Riset dan Pengembangan Kementerian Riset, Teknologi, dan Pendidikan Tinggi sesuai dengan Kontrak Penelitian Tahun Anggaran 2018 